\title{
Biological Synthesis of Silver Nanoparticles from Anisomeles Indica and their Mosquito Efficacy
}

\section{Veera Kumar $\mathbf{K}^{*}$ and Govindarajan $\mathbf{M}$ \\ Department of Zoology, Annamalai University, India}

*Corresponding author: Kaliyan Veera Kumar, Department of Zoology, Unit of Vector Control, Phytochemistry and Nanotechnology, Annamalai University, Annamalai Nagar-608002, Tamil Nadu, India, Tel: 9786191747; Email: kvkumarj10@gmail.com

\section{Research Article}

Volume 2 Issue 5

Received Date: September 25, 2019

Published Date: October 10, 2019

DOI: $10.23880 /$ izab-16000176

\section{Abstract}

Mosquitoes transmit serious human diseases, causing millions of deaths every year. The use of synthetic insecticides to control vector mosquitoes has caused physiological resistance and adverse environmental effects in addition to high operational cost. The use of synthetic mosquitocides often leads to high operational costs and adverse non-target effects. Recently, plant borne compounds have been proposed for rapid extracellular biosynthesis of mosquitocidal nanoparticles. However, the impact of these nano mosquitocides against biological control agents of mosquito larval populations has been poorly studied. The present study was carried out to establish the larvicidal potential of leaf extracts of Anisomeles indica and synthesized silver nanoparticles using aqueous leaf extract against late third instar larvae of Anopheles stephensi, Aedes aegypti, and Culex quinquefasciatus. Larvae were exposed to varying concentrations of plant extracts and synthesized AgNPs for 24 hours. The results were recorded from UV-visible spectroscopy, Fourier transform infrared spectroscopy, scanning electron microscopy, transmission electron microscopy, and energydispersive X-ray spectroscopy analysis support the biosynthesis and characterization of AgNPs. The maximum efficacy was observed in synthesized AgNPs against the larvae of An. stephensi (lethal concentration $\left(\mathrm{LC}_{50}\right)=25.67 \mu \mathrm{g} / \mathrm{mL}$; $\mathrm{LC}_{90}$ $50.09 \mu \mathrm{g} / \mathrm{mL})$, Ae.aegypti ( $\mathrm{LC}_{50}=27.40 \mu \mathrm{g} / \mathrm{mL} ; \mathrm{LC}_{90} 53.05 \mu \mathrm{g} / \mathrm{mL}$ ), and Cx. quinquefasciatus (LC ${ }_{50}=29.67 \mu \mathrm{g} / \mathrm{mL} ; \mathrm{LC}_{90}$ $57.28 \mu \mathrm{g} / \mathrm{mL}$ ), respectively. No mortality was observed in the control. This is the first report on mosquito larvicidal activity of plant-synthesized nanoparticles. Thus, the use of A.indica to synthesize silver nanoparticles is a rapid, ecofriendly, and a single-step approach and the Ag NPs formed can be potential mosquito larvicidal agents.

Keywords: Anopheles Stephensi; Anisomeles Indica; Larvicides; Mosquitoes 


\section{International Journal of Zoology and Animal Biology}

\section{Introduction}

Mosquitoes constitute a major public health problem as vectors of serious human diseases like malaria, filariasis, Japanese encephalitis, dengue fever, chikungunya, and yellow fever that cause substantial mortality and morbidity among people living in tropical and subtropical zones [1]. Aedes aegypti is generally known as a vector for an arbovirus responsible for dengue fever, which is endemic to Southeast Asia, the Pacific island area, Africa, and the Americas. This mosquito is also the vector of yellow fever in Central and South America and West Africa. Dengue fever has become an important public health problem as the number of reported cases continues to increase, especially with more severe forms of the disease, dengue hemorrhagic fever, and dengue shock syndrome or with unusual manifestations such as central nervous system involvement. Dengue is prevalent in more than 100 countries and threatens the health of approximately 2.5 billion People. Around 80 million people are infected annually at an attack rate of $4 \%$ worldwide [2]. Anopheles stephensi is the primary vector of malaria in India and other West Asian countries, and improved methods of control are urgently needed [3]. Malaria caused by Plasmodium falciparum is one of the leading causes of human morbidity and mortality from infectious diseases, predominantly in tropical and subtropical countries [4]. Mosquito bites may also cause allergic responses including local skin reactions and systemic reactions such as urticaria and angioedema [5].

Culex quinquefasciatus is a predominant house resting mosquito in many tropical countries. It is important as a vector of filariasis in some countries as well as a nuisance mosquito. Mosquitoes breed in polluted waters such as blocked drains, damaged septic tanks or soak age pools close to human habitations. Lymphatic filariasis is probably the fastest spreading insect-borne disease of man in the tropics, affecting about 146 million people [6]. $C x$. quinquefasciatus is the most widely distributed mosquito in India, mainly found in urban and suburban areas. The most efficient approach to control the vector is to target the immature stages of the life cycle. Bancroftian filariasis, caused by Wuchereria bancrofti and transmitted by the tropical house mosquito $C x$. quinquefasciatus, accounts for $95 \%$ of the total lymphatic filariasis cases in India. Control of mosquito vector-borne diseases is becoming difficult because of the increasing resistance of mosquitoes to pesticides [7]. Lymphatic filariasis is a mosquito-borne disease caused by mosquito-transmitted filarial nematodes, including $W$. bancrofti and Brugia malayi. The infected people carry the nocturnally periodic $W$. bancrofti, which has $C x$. quinquefasciatus as the main mosquito vector. $C x$. quinquefasciatus is a vector of lymphatic filariasis, which is a widely distributed tropical disease with around 120 million people infected worldwide and 44 million people have common chronic manifestation [8]. According to WHO, about 90 million people worldwide are infected with $W$. bancrofti, the lymphatic-dwelling parasite, and ten times more people ate at the risk of being infected. In India alone, 25 million people harbour microfilaria and 19 million people suffer from filarial disease manifestations $[9,10]$.

Plants are rich source of alternative agents for control of mosquitoes, because they possess bioactive chemicals, which act against limited number of species including specific target insects and are eco-friendly [11]. Traditionally, plant-based products have been used in human communities for many centuries for managing insects. Several secondary metabolites present in plants serve as a defense mechanism against insect attacks. These bioactive chemicals may act as insecticides, antifeedants, molting hormones, oviposition deterrents, repellents, juvenile hormone mimics, growth inhibitors, anti molting hormones, as well as attractants. Plant-based pesticides are less toxic, delay the development of resistance because of its new structure, and easily biodegradable [12]. Search for eco-safe, low-cost, and a highly potential insecticide for the control of mosquitoes needs the preliminary screening of plants to evaluate their insecticidal activities. Plant-based products do not have any hazardous effect on ecosystem. Recent research has proved that effectiveness of plant-derived compounds, such as saponine [13]. These attempts to develop novel materials as mosquito larvicides are still necessary. With the progress of nano-technology, many laboratories around the world have investigated silver nanoparticle (AgNPs) production as the nanoparticle possesses more surface atoms than a micro particle, which greatly improves the particle's physical and chemical characteristics. Some physical or chemical methods that are currently available for silver nanoparticle production include mechanical smashing, a solid-phase reaction, freeze-drying, spread drying, and precipitation (co- and homo-precipitation). In general, these methods consume a lot of energy in order to maintain the high pressures and temperatures that are needed for them to work. In contrast, many bioprocesses occur under normal air pressure and temperature, resulting in vast energy savings. As a consequence, this type of procedure attracted the attention of microbiologists and chemists [14]. 


\section{International Journal of Zoology and Animal Biology}

Phytochemicals with mosquitocidal potential are now recognized as potent alternative insecticides to replace synthetic insecticides in mosquito control programs due to their excellent larvicidal, pupicidal, and adulticidal properties. Many synthetic insecticides and naturally occurring chemical cues have been shown to influence mosquito oviposition $[10,15,16]$. The chemicals derived from plants have been projected as weapons in future mosquito control program as they are shown to function as general toxicant, growth and reproductive inhibitors, repellents, and oviposition deterrent [11]. The pediculocidal and larvicidal activities of synthesized silver nanoparticles using the aqueous leaf extract of Tinospora cordifolia have been reported against the human capitis and fourth instar larvae of An. subpictus and $C x$. quinquefasciatus [17] .The larvicidal efficacy of the crude leaf extracts of Ficus benghalensis, with three different solvents like methanol, benzene, and acetone, were tested against the early second, third, and fourth instar larvae of Cx. quinquefasciatus, Ae.aegypti, and An. Stephensi [18]. The activity of aqueous leaf extract and silver nanoparticles (AgNPs) synthesized using H.indicum plant leaves against late third instar larvae of Ae.aegypti, An. stephensi and $C x$. Quinquefasciatus [19]. The adulticidal and repellent activities of crude hexane, ethyl acetate, benzene, chloroform, and methanol extracts of leaf of Eclipta alba and A. paniculata were assayed for their toxicity against two important vector mosquitoes, viz., $C X$. quinquefasciatus and Ae.aegypti [20]. The larvicidal activity of silver nanoparticles (AgNPs) synthesized using Feronia elephantum plant leaf extract against late third instar larvae of An.stephensi, Ae.aegypti, and $C x$. Quinquefasciatus [21]. They found that the silver nanoparticles were more effective against the mosquito larval stages than the gold nanoparticles. The larvicidal efficacy of the aqueous and methanol extracts from green unripe to yellow ripe fruits of Solanum xanthocarpum was effective in controlling An. culicifacies, An.stephensi, Ae.aegypti, and Cx. quinquefasciatus [22].

The larvicidal and repellent properties of essential oils is from various parts of four plant species Cymbopogon citratus, Cinnamomum zeylanicum, Rosmarinus officinalis, and Zingiber officinale against $C x$. tritaeniorhynchus and An. Subpictus [22]. Elumalai, et al. [23] have reported that the aqueous extract of shade dried leaves of Euphorbia hirta was used for the synthesis of AgNPs and their antibacterial activities. The adulticidal activity of silver nanoparticles (AgNPs) synthesized using F. elephantum plant leaf extract against adults of An. stephensi, Ae. aegypti, and $C x$. quinquefasciatus $[24,25]$.

The larvicidal activity of silver nanoparticles synthesized using Pergularia daemia plant latex has been screened against the Ae. aegypti, An. stephensi, and nontarget fish Poecillia reticulata [26]. Essential oil of Cinnamomum zeylanicum showed oviposition-deterrent and repellent activities, and the essential Oils of Zingiber officinale and Rosmarinus officinalis also showed both ovicidal and repellent activities against An. stephensi, Ae. aegypti, and Cx. quinquefasciatus [27]. The larvicidal activity of silver nanoparticles (AgNPs) synthesized using Sida acuta plant leaf extract against late third instar larvae of CX. quinquefasciatus, An. stephensi, and Ae. aegypti [10]. Biolarvicidal and pupicidal potential of silver nanoparticles synthesized with E. hirta has been Screened against the larvae of An. stephensi [28]. The leaf extract of Acalypha indica with different solvents benzene, chloroform, ethyl acetate, and methanol has been tested for larvicidal-ovicidal activity and oviposition attractancy against An. stephensi [29]. They found that the silver nanoparticles were more effective against the mosquito larval stages than the gold nanoparticles. The silver nanoparticles synthesized with Nelumbo nucifera leaf extract have been tested against the malaria and filariasis vectors [30]. In the current study, the larvicidal activity of AgNPs synthesized using Anisomeles indica leaf extract was assessed under laboratory conditions. We report the synthesis of AgNPs, reducing the silver ions present in the solution of silver nitrate by the cell-free aqueous leaf extract of $A$. indica. However, these biologically synthesized nanoparticles (NPs) and aqueous extract of $A$. indica were found to produce a significant mosquitocidal activity against target species. The first time against larvae of dengue (Ae. aegypti), malaria (An. stephensi), and filariasis ( $C x$. quinquefasciatus) vector mosquitoes.

\section{Materials and Methods}

\section{Collection of Materials}

Fresh leaves of Anisomeles indica (Figure 1) were collected from in and around Bhuvanagiri, Chidambaram and Tamil Nadu, and the taxonomic identification was made by Department of Botany, Annamalai University, Annamalai Nagar, Tamil Nadu, and The voucher specimen was numbered and kept in our research laboratory for further reference. Silver nitrate was obtained from Qualigens Fine Chemicals, Mumbai, India. 


\section{International Journal of Zoology and Animal Biology}

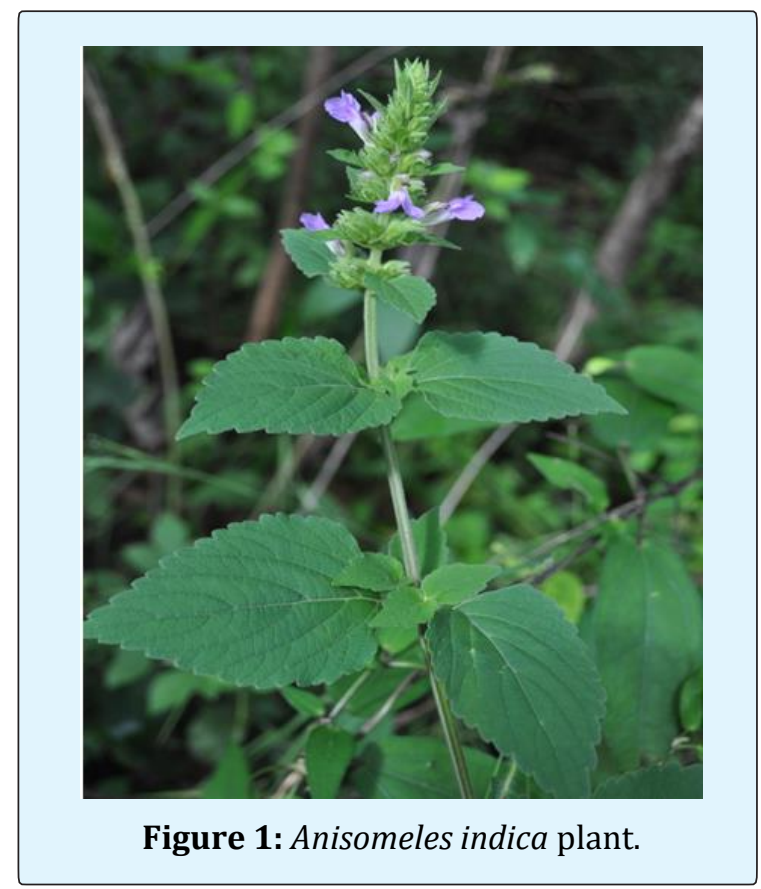

\section{Mosquitoes}

The laboratory-bred pathogen-free strains of mosquitoes were reared in the vector control laboratory, Department of Zoology, Annamalai University. At the time of adult feeding, these mosquitoes were 3-4 days old after emergences (maintained on raisins and water) and were starved for $12 \mathrm{~h}$ before feeding. Each time, 500 mosquitoes per cage were fed on blood using a feeding unit fitted with parafilm as membrane for 4 hours. Ae. aegypti feeding was done from 12 noon to 4.00 p.m. and $A n$. stephensi and $C x$. quinquefasciatus were fed during 6.00 p.m. to 10.00 p.m. A membrane feeder with the bottom end fitted with parafilm was placed with $2.0 \mathrm{ml}$ of the blood sample (obtained from a slaughter house by collecting in a heparinized vial and stored at $4^{\circ} \mathrm{C}$ ) and kept over a netted cage of mosquitoes. The blood was stirred continuously using an automated stirring device, and a constant temperature of $37^{\circ} \mathrm{C}$ were maintained using a water jacket circulating system. After feeding, the fully engorged females were separated and maintained on raisins. Mosquitoes were held at $28 \pm 2^{\circ} \mathrm{C}, 70-85 \%$ relative humidity, with a photo period of 12 -h light and 12-h dark.

\section{Preparation of Plant Extracts}

The leaves A.indica were dried in the shade and ground to fine powder in an electric grinder. Aqueous extract was prepared by mixing $50 \mathrm{~g}$ of dried leaf powder with $500 \mathrm{~mL}$ of water (boiled and cooled distilled water) with constant stirring on a magnetic stirrer [19]. The suspension of dried leaf powder in water was left for $3 \mathrm{~h}$ and filtered through Whatman no. 1 filter paper and the filtrate were stored in an amber-colored airtight bottle at $10^{\circ} \mathrm{C}$ temperature till use.

\section{Synthesis of Silver Nanoparticles}

The broth solution of fresh A.indica leaves was prepared by taking $10 \mathrm{~g}$ of thoroughly washed and finely cut leaves in a $300-\mathrm{mL}$ Erlenmeyer flask along with 100 $\mathrm{mL}$ of sterilized double-distilled water and then boiling the mixture for $5 \mathrm{~min}$ before finally decanting it. The extract was filtered with Whatman filter paper no. 1 and stored at $15^{\circ} \mathrm{C}$; it could be used within 1 week. The filtrate was treated with aqueous $1 \mathrm{mM} \mathrm{AgNO}_{3}\left(21.2 \mathrm{mg}\right.$ of $\mathrm{AgNO}_{3}$ powder in $125 \mathrm{~mL}$ Milli-Q water) solution in an Erlenmeyer flask and incubated at room temperature. Eighty-eight milliliters of an aqueous solution of $1 \mathrm{mM}$ silver nitrate was reduced using $12 \mathrm{~mL}$ of leaf extract at room temperature for $10 \mathrm{~min}$, resulting in a brownyellow solution indicating the formation of AgNPs (Figures 2a \& 2b) [10]. 

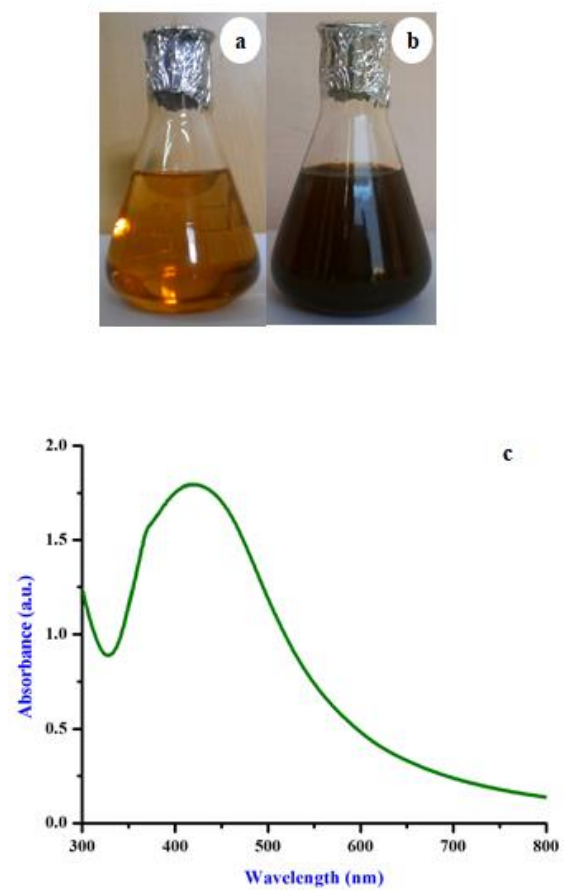

Figure 2: a and b Color intensity of biosynthesized silver nanoparticles from aqueous extract of Anisomeles indica c. Color intensity of UV spectral peak of biosynthesized AgNPs.

\section{Characterization of the Synthesized Nanoparticles}

Synthesis of AgNPs solution with leaves extract may be easily observed by UV-vis spectroscopy. The bio reduction of the Ag+ ions in solutions was monitored by periodic sampling of aliquots $(1 \mathrm{~mL})$ of the aqueous component after 20 times dilution and measuring the UVvis spectra of the solution. UV-vis spectra of these aliquots were monitored as a function of time of reaction on a Schimadzu 1601 spectrophotometer in 300-700-nm range operated at a resolution of $1 \mathrm{~nm}$. Further, the reaction mixture was subjected to centrifugation at $60,000 \times \mathrm{g}$ for $40 \mathrm{~min}$; resulting pellet was dissolved in deionized water and filtered through Millipore filter ( 0.45 $\mu \mathrm{m})$. Fourier transform infrared (FTIR) spectra of the samples were measured using a Perkin-Elmer Spectrum One instrument in the diffuse reflectance mode at a resolution of $4 \mathrm{~cm}^{-1}$ in $\mathrm{KBr}$ pellets. Powder samples for the FTIR was prepared similarly as for powder diffraction measurements. An aliquot of this filtrate containing silver nanoparticles was used for X- ray diffraction (XRD), FTIR, and analysis. For XRD studies, dried nanoparticles were coated on the XRD grid, and the spectra were recorded using Phillips PW 1830 instrument operating at a voltage of $40 \mathrm{kV}$ and a current of $30 \mathrm{~mA}$ with $\mathrm{CuK} \alpha 1$ radiation. For electron microscopic studies, $25 \mu \mathrm{L}$ of sample was sputter-coated on copper stub, and the images of nanoparticles were studied using scanning electron microscopy (SEM; JEOL, Model JFC-1600) and transmission electron microscopy (TEM; JEOL, model 1200EX) measurements were operated at an accelerating voltage of $120 \mathrm{kV}$ and later with an XDL 3000 powder.

\section{Larvicidal activity}

Larvicidal activity of the aqueous crude extract and AgNPs from A. indica was evaluated according to WHO protocol [31]. Based on the wide range and narrow range tests, aqueous crude extract was tested at 40, 80,120,160 and $200 \mu \mathrm{g} / \mathrm{mL}$ concentrations and AgNPs was tested at $8,16,24,32$, and $40 \mu \mathrm{g} / \mathrm{mL}$ concentrations. Twenty numbers of late third instar larvae were introduced into a $500-\mathrm{mL}$ glass beaker containing $249 \mathrm{~mL}$ of dechlorinated water and $1 \mathrm{~mL}$ of desired concentrations of leaf extract and silver nanoparticles was added. For each concentration, five replicates were performed, for a total 
of 100 larvae. Larval mortality was recorded at $24 \mathrm{~h}$ after exposure, during which no food was given to the larvae. Each test included a set control groups (silver nitrate and distilled water) with five replicates for each individual concentration. The lethal concentrations $\left(\mathrm{LC}_{50}\right.$ and $\mathrm{LC}_{90}$ ) were calculated by probit analysis [32].

\section{Statistical Analysis}

The average adult mortality data were subjected to probit analysis for calculating $\mathrm{LC}_{50}, \mathrm{LC}_{90}$, and other statistics at $95 \%$ confidence limits of upper confidence limit and lower confidence limit, and chi-square values were calculated using the Statistical Package of Social Sciences 12.0 software. Results with $\mathrm{p}<0.05$ were considered to be statistically significant.

\section{Results}

\section{Larvicidal Activity of Aqueous Extract and Synthesized Agnps}

Larvicidal activity of aqueous extract and synthesized AgNPs the results of larvicidal activity of the A.indica aqueous leaf extract against late third-instar An. stephensi, Ae.aegypti, and $C x$. quinquefasciatus were noted and presented in Table 1. Considerable mortality was evident after the treatment of A.indica for all three important vector mosquitoes. The $\mathrm{LC}_{50}$ and $\mathrm{LC}_{90}$ values of the A.indica aqueous leaf extract appeared to be effective against An. stephensi $\left(\mathrm{LC}_{50}, 92.58 \mu \mathrm{g} \mathrm{mL}^{-1}\right.$, and $\mathrm{LC}_{90}$, $179.58 \mu \mathrm{g} \mathrm{mL}^{-1}$ ) followed by Ae.aegypti $\mathrm{LC}_{50}(99.02 \mu \mathrm{g}$ $\mathrm{mL}^{-1}$ and $\mathrm{LC}_{90}, 121.07 \mu \mathrm{g} \mathrm{mL}^{-1}$ ) and C. quinquefasciatus ( $\mathrm{LC}_{50}, 106.23 \mu \mathrm{g} \mathrm{mL}-1$, and $\mathrm{LC}_{90}, 198.93 \mu \mathrm{g} \mathrm{mL}{ }^{-1}$ ). Considerable mortality was evident after the treatment of silver nanoparticles. Synthesized AgNPs against the vector mosquitoes An.stephensi, Ae.aegypti, and $C X$. quinquefasciatus had the following $\mathrm{LC}_{50}$ and $\mathrm{LC}_{90}$ values: An. stephensi had $\mathrm{LC}_{50}$ and $\mathrm{LC}_{90}$ values of 25.67 and 50.09 $\mu \mathrm{gmL}^{-1} ;$ Ae. aegypti had $\mathrm{LC}_{50}$ and $\mathrm{LC}_{90}$ values of 27.40 and $53.05 \mu \mathrm{g} \mathrm{mL}-1$; and $C x$. quinquefasciatus had $\mathrm{LC}_{50}$ and $\mathrm{LC}_{90}$ values of 29.67 and $57.28 \mu \mathrm{g} \mathrm{mL}^{-1}$ (Table 2 \& Figure 2). The control showed nil mortality in the concurrent assay. $\chi 2$ value was significant at the $\mathrm{p} \leq 0.05$ level.

\begin{tabular}{|c|c|c|c|c|c|}
\hline Mosquitoes & Concentration & 24 h mortality $(\%) \pm S D$ & $\mathrm{LC}_{50}(\mu \mathrm{g} / \mathrm{mL})(\mathrm{LCL}-\mathrm{UCL})$ & $\mathrm{LC}_{90}(\mu \mathrm{g} / \mathrm{mL})(\mathrm{LCL}-\mathrm{UCL})$ & $\chi^{2}$ \\
\hline \multirow{6}{*}{ An.stephensi } & Control & $0.0 \pm 0.0$ & 92.58 & 179.58 & \\
\hline & 40 & $28.2 \pm 1.5$ & $(50.899-121.613)$ & $(144.596-280.981)$ & $12.065^{*}$ \\
\hline & 80 & $40.1 \pm 1.2$ & & & \\
\hline & 120 & $58.2 \pm 0.8$ & & & \\
\hline & 160 & $80.3 \pm 1.4$ & & & \\
\hline & 200 & $100.0 \pm 0.0$ & & & \\
\hline \multirow{6}{*}{ Ae.aegypti } & Control & $0.0 \pm 0.0$ & 99.02 & 121.07 & \\
\hline & 40 & $26.1 \pm 1.4$ & $(52.43-84.53)$ & $(61.139-127.985)$ & 11.024* \\
\hline & 80 & $37.5 \pm 1.8$ & & & \\
\hline & 120 & $54.3 \pm 1.2$ & & & \\
\hline & 160 & $76.1 \pm 0.9$ & & & \\
\hline & 200 & $98.4 \pm 1.4$ & & & \\
\hline \multirow{6}{*}{ Cx.quinquefasciatus } & Control & $0.0 \pm 0.0$ & 106.23 & 198.93 & \\
\hline & 40 & $24.3 \pm 1.6$ & $(73.431-134.344)$ & $(162.810-293.801)$ & 9.792* \\
\hline & 80 & $32.1 \pm 1.1$ & & & \\
\hline & 120 & $51.4 \pm 0.9$ & & & \\
\hline & 160 & $73.1 \pm 1.5$ & & & \\
\hline & 200 & $96.2 \pm 0.8$ & & & \\
\hline
\end{tabular}

SD standard deviation, LCL lower confidence limits, UCL upper confidence limits, $\chi 2$ Chi-square test ${ }^{*} \mathrm{p}<0.05$, level of significance

a Values are mean \pm SD of five replicates

Table 1: Larvicidal activity of Anisomeles indica aqueous leaf extracts against Anopheles stephensi, Aedes aegypti, and Culex quinquefasciatus. 


\section{International Journal of Zoology and Animal Biology}

\begin{tabular}{|c|c|c|c|c|c|}
\hline Mosquitoes & Concentration & 24 h mortality (\%) \pm SD & $\mathrm{LC}_{50}(\mu \mathrm{g} / \mathrm{mL})(\mathrm{LCL}-\mathrm{UCL})$ & $\mathrm{LC}_{90}(\mu \mathrm{g} / \mathrm{mL})(\mathrm{LCL}-\mathrm{UCL})$ & $\chi^{2}$ \\
\hline \multirow{6}{*}{ An.stephensi } & Control & $0.0 \pm 0.0$ & 25.67 & 50.09 & \\
\hline & 8 & $27.1 \pm 0.8$ & $(22.879-28.176)$ & $(46.460-54.893)$ & 7.370* \\
\hline & 16 & $47.4 \pm 1.2$ & & & \\
\hline & 24 & $63.2 \pm 1.4$ & & & \\
\hline & 32 & $86.3 \pm 0.9$ & & & \\
\hline & 40 & $100.0 \pm 0.0$ & & & \\
\hline \multirow{6}{*}{ Ae.aegypti } & Control & $0.0 \pm 0.0$ & 27.4 & 53.05 & \\
\hline & 8 & $25.2 \pm 1.3$ & $(24.585-29.955)$ & $(49.172-58.209)$ & $6.001^{*}$ \\
\hline & 16 & $44.1 \pm 1.6$ & & & \\
\hline & 24 & $60.2 \pm 1.2$ & & & \\
\hline & 32 & $82.3 \pm 0.8$ & & & \\
\hline & 40 & $98.7 \pm$ & & & \\
\hline \multirow{6}{*}{ Cx.quinquefasciatus } & Control & $0.0 \pm 0.0$ & 29.67 & 57.28 & \\
\hline & 8 & $23.1 \pm 1.2$ & $(26.79-32.322)$ & $(52.945-68.109)$ & 4.969* \\
\hline & 16 & $41.3 \pm 1.6$ & & & \\
\hline & 24 & $55.2 \pm 1.4$ & & & \\
\hline & 32 & $77.4 \pm 1.8$ & & & \\
\hline & 40 & $96.1 \pm 0.8$ & & & \\
\hline
\end{tabular}

SD standard deviation, LCL lower confidence limits, UCL upper confidence limits, $\chi 2$ Chi-square test ${ }^{*} \mathrm{p}<0.05$, level of significance a Values are mean \pm SD of five replicates.

Table 2: Larvicidal activity of silver nanoparticles against Anopheles stephensi, Aedes aegypti, and Culex quinquefasciatus.

\section{Characterization of Silver Nanoparticles}

The change in color was noted by visual observation in the A.indica extract when it was incubated with $\mathrm{AgNO}_{3}$ solution. A.indica extract without $\mathrm{AgNO}_{3}$ did not show any change in color (Figure 3a \& b). The color of the extract changed to light brown within an hour and then later changed to dark brown during the 30 min incubation period. No significant change occurred after $30 \mathrm{~min}$. The absorption spectrum of A.indica extract at different wavelengths ranging from 300 to $800 \mathrm{~nm}$ revealed a peak at $420 \mathrm{~nm}$ (Figure 3c). FTIR analysis of the purified nanoparticles showed the presence of bands due to $\mathrm{C}-\mathrm{H}$ "oop" group (824.68), C-O stretch (111.49), N-H bend (1582.96), O-H stretch (2962.28), and O-H stretch (3373.57) (Figure 4). SEM micrographs of the synthesized AgNPs of $A$. indica magnified at $\times 5,000$, times its size was measured at 20 to $60 \mathrm{~nm}$ are shown in (Figure 5a). It is clear that the triangles, pentagons, and hexagons structures. EDX proves the chemical purity of the synthesized AgNPs (Figure 5b). The electron microscopic study of the nanoparticles using TEM revealed that the nano-Ag predominates with spherical, triangle, truncated triangles, and decahedral morphologies ranging from 18 to $35 \mathrm{~nm}$ with an average size of $30 \mathrm{~nm}$ (Figure 6). The Xray diffraction pattern of silver nanoparticles produced by leaf extract is shown in (Figure 7). The control thin films of the leaf extract as well as the AgNO3 did not show the characteristic peaks. The XRD pattern shows four intense peaks in the whole spectrum of $2 \theta$ values ranging from 25 to 60 . The XRD spectrum compared with the standard confirmed spectrum of silver particles formed in the present experiments were in the form of nano crystals, as evidenced by the peaks at $2 \theta$ values of $38.22^{\circ}, 44.37^{\circ}$, $64.54^{\circ}$, and $77.47^{\circ}$ corresponding to $65,23,14$, and 15 planes for silver, respectively. The XRD pattern clearly shows that the silver nanoparticles formed by the reduction of $\mathrm{Ag} \mathrm{NO}_{3}$ ions by A.indica are crystalline in nature. 


\section{International Journal of Zoology and Animal Biology}
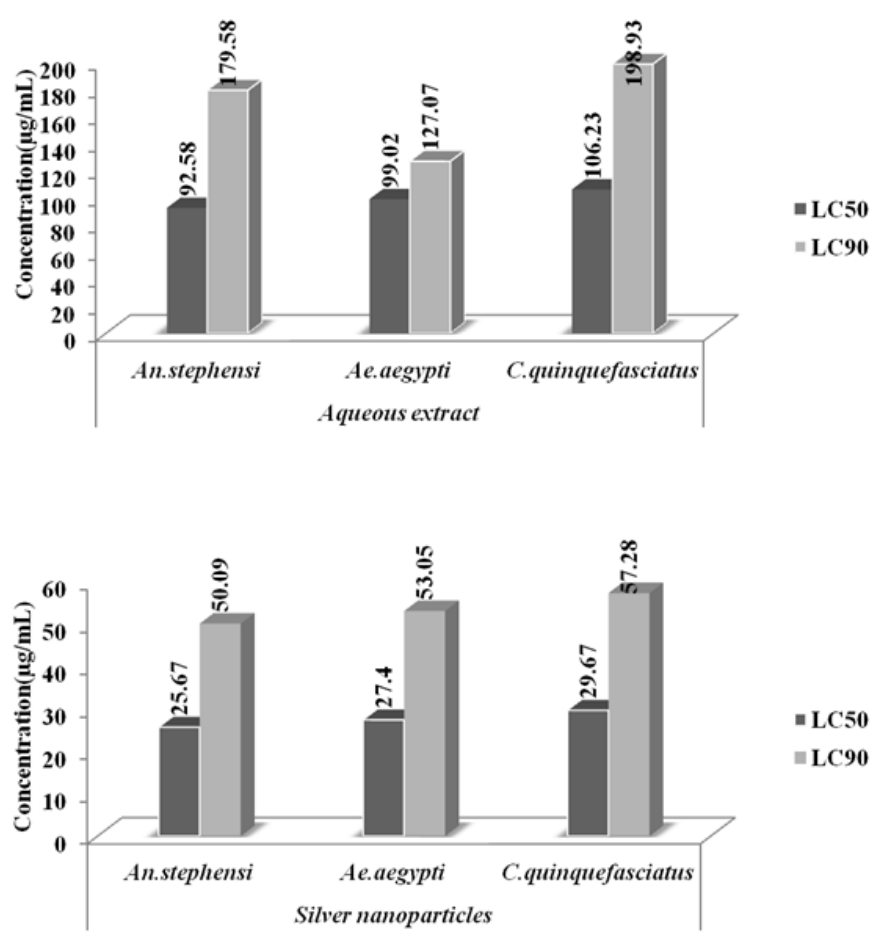

Figure 3: Graph showing the a and b, LC50 and LC90 values of larvicidal activity of A.indica aqueous leaf extract and silver nanoparticles against Anopheles stephensi, Aedes aegypti, and Culex quinquefasciatus.

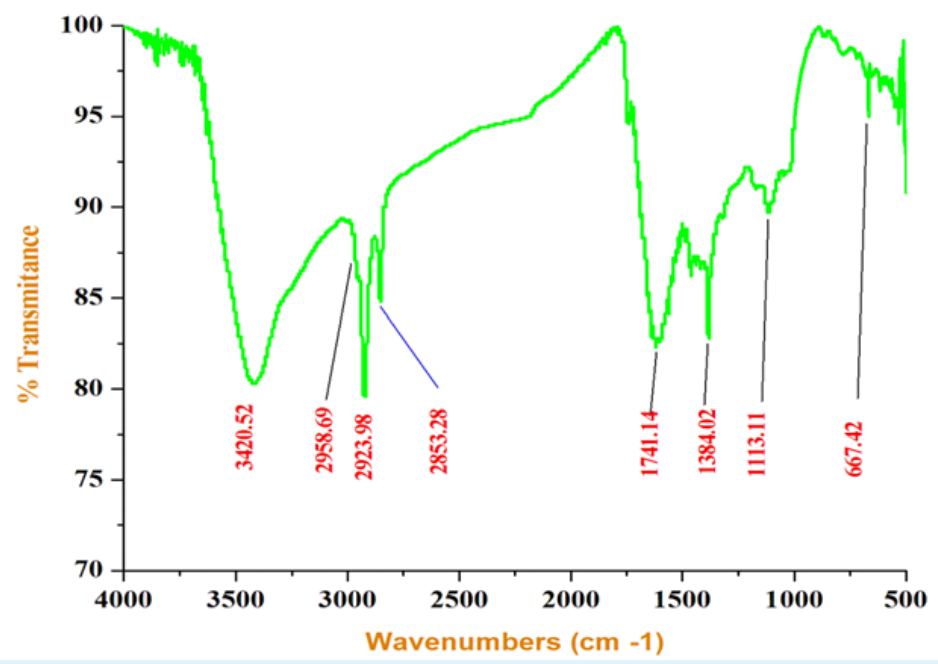

Figure 4: FT-IR spectrum of synthesized AgNPs using Anisomeles indica leaf extract. 


\section{International Journal of Zoology and Animal Biology}
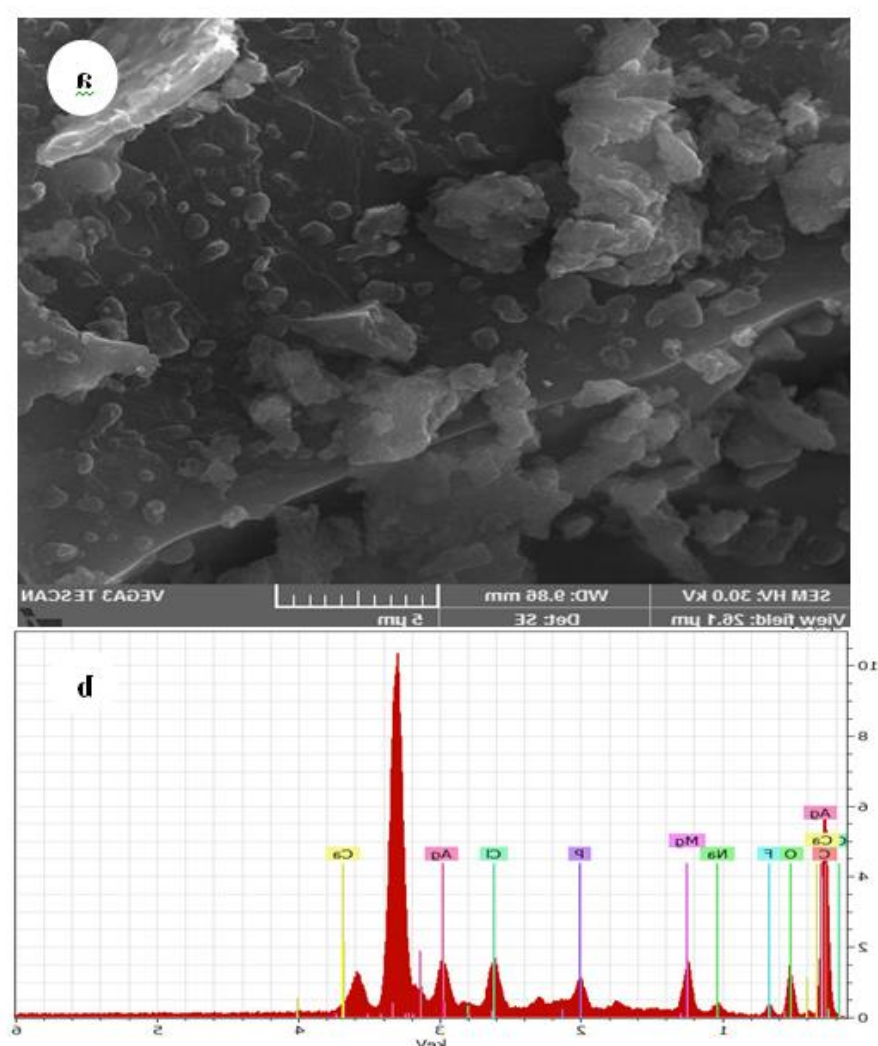

Figure 5: Scanning electron micrographs of AgNPs synthesized with Anisomeles indica leaf extract and $1.0 \mathrm{mM} \mathrm{AgNO}_{3}$ solution and incubated at $60^{\circ} \mathrm{C}$ for $6 \mathrm{~h}$ at $\mathrm{pH} 7.0$ a. $5 \mu$ magnified inset bar represents; c. EDX image showing chemical composition.

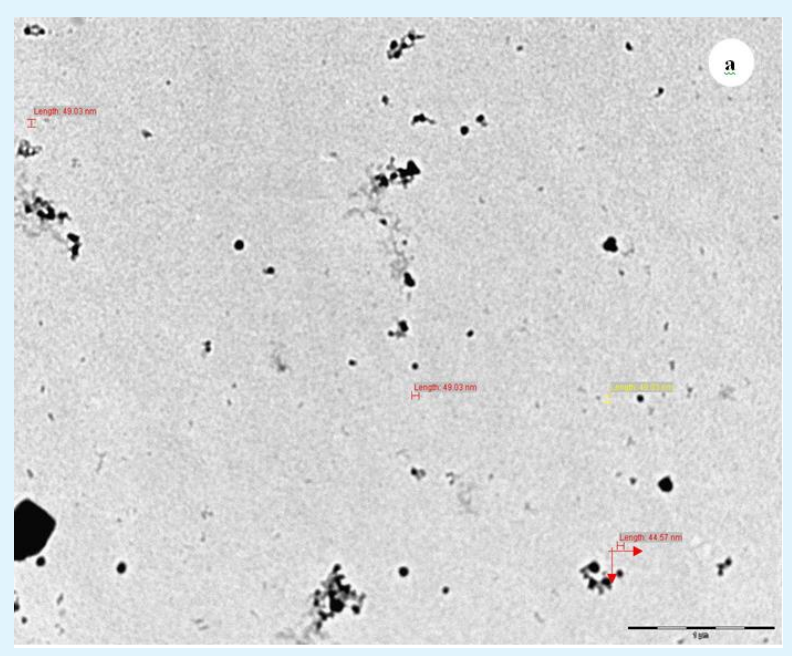

Figure 6: Transmission electron microscopic image and histogram showing synthesized AgNPs from Anisomeles indica 


\section{International Journal of Zoology and Animal Biology}

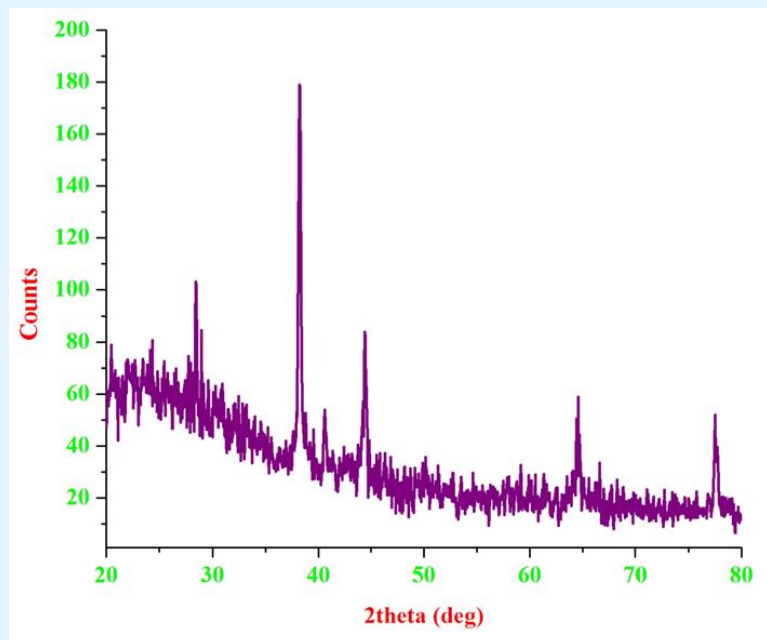

Figure 7: X-Ray diffraction showing synthesized AgNPs from Anisomeles indica.

\section{Discussion}

The broad spectrum properties of silver nanoparticles have attracted researchers to evaluate their potential against the parasites of world's most threatening diseases, malaria, dengue and filariasis. Phytochemicals may serve as these are relatively safe, inexpensive, and readily available in many parts of the world. Several plants are used in traditional medicines for the mosquito larvicidal activities in many parts of the world. The ethnopharmacological approaches used in the search of new bioactive toxins from plants appear to be predictive compared to the random screening approach. The recently developed new isolation techniques and chemical characterization through different types of spectroscopy and chromatography together with new pharmacological testing have led to an interest in plants as the source of new larvicidal compounds. Synergestic approaches such as application of mosquito predators with botanical blends and microbial pesticides will provide a better effect in reducing the vector population and the magnitude of epidemiology. The larvicidal aqueous crude leaf extracts and synthesized silver nanoparticles of M. pudica showed the highest mortality in synthesized AgNPs against the larvae of An. subpictus and $C x$. quinquefasciatus $\left(\mathrm{LC}_{50} 13.90\right.$ and $11.73 \mathrm{mg} / \mathrm{L} ; \mathrm{r}=$ 200.411 and 0.286), respectively [33]. In Nelumbo nucifera leaf, synthesized AgNPs' maximum efficacy was observed in crude methanol, aqueous, and synthesized AgNPs against the larvae of An. subpictus ( $\mathrm{LC}_{50}$ 08.89,
11.82, and $0.69 \mathrm{ppm}$, respectively; $\mathrm{LC}_{90} 28.65,36.06$, and $2.15 \mathrm{ppm}$, respectively) and against the larvae of $C X$. quinquefasciatus $\left(\mathrm{LC}_{50}\right.$ 09.51, 13.65, and $1.10 \mathrm{ppm}$, respectively; $\mathrm{LC}_{90} 28.13,35.83$, and $3.59 \mathrm{ppm}$, respectively) [30].

The $\mathrm{LC}_{50}$ and $\mathrm{LC}_{90}$ values of the F. elephantum aqueous leaf extract appeared to be effective against An. stephensi ( $\mathrm{LC}_{50}, 54.88 \mu \mathrm{g} \mathrm{mL}^{-1}$, and $\mathrm{LC}_{90}, 97.38 \mu \mathrm{g} \mathrm{mL}^{-1}$ ) followed by Ae.aegypti $\mathrm{LC}_{50}\left(62.02 \mu \mathrm{g} \mathrm{mL}^{-1}\right.$ and $\left.\mathrm{LC}_{90}, 110.71 \mu \mathrm{g} \mathrm{mL}^{-1}\right)$ and C. quinquefasciatus $\left(\mathrm{LC}_{50}, 67.08 \mu \mathrm{g} \mathrm{mL}^{-1}\right.$, and $\mathrm{LC}_{90}$, $117.85 \mu \mathrm{g} \mathrm{mL}^{-1}$ ) [24]. The larvicidal activity of ethyl acetate extract of $M$. pudica showed the LD50 $=134.66$, 156.55, and $112.78 \mathrm{ppm}$; LD90 $=921.14,1,214.47$, and 627.80 against $C x$. gelidus and $\mathrm{LD}_{50}=134.15,152.64$, and $115.66 \mathrm{ppm}$; and $\mathrm{LD}_{90}=633.38,781.63$, and 485.12 against $C x$. quinquefasciatus, respectively [33]. The $\mathrm{LC}_{50}$ and $\mathrm{LC}_{90}$ values of $H$. indicum aqueous leaf extract appeared to be effective against An. stephensi $\left(\mathrm{LC}_{50}, 68.73\right.$ $\mu \mathrm{g} / \mathrm{mL} ; \mathrm{LC}_{90}, 121.07 \mu \mathrm{g} / \mathrm{mL}$ ) followed by Ae.aegypti ( $\mathrm{LC}_{50}$, $\left.72.72 \mu \mathrm{g} / \mathrm{mL} ; \quad \mathrm{LC}_{90}, 126.86 \mu \mathrm{g} / \mathrm{mL}\right)$ and $C$. quinquefasciatus $\quad\left(\mathrm{LC}_{50}, 78.74 \mu \mathrm{g} / \mathrm{mL} ; \quad \mathrm{LC}_{90}, 134.39\right.$ $\mu \mathrm{g} / \mathrm{mL}$ ). Most considerable mortality was evident after the treatment of silver nanoparticles synthesized AgNPs against the vector mosquitoes of An. stephensi, Ae.aegypti, and $C x$. quinquefasciatus had the following $\mathrm{LC}_{50}$ and $\mathrm{LC}_{90}$ values: An. stephensi had $\mathrm{LC}_{50}$ and $\mathrm{LC}_{90}$ values of 18.40 and $32.45 \mu \mathrm{g} / \mathrm{mL}$, Ae aegypti had $\mathrm{LC}_{50}$ and $\mathrm{LC}_{90}$ values of 20.10 and $35.97 \mu \mathrm{g} / \mathrm{mL}$ and Cx.quinquefasciatus had $\mathrm{LC}_{50}$ and $\mathrm{LC}_{90}$ values of 21.84 and $38.10 \mu \mathrm{g} / \mathrm{mL}$ respectively [19]. 


\section{International Journal of Zoology and Animal Biology}

Ecotoxicity study was determined by Ag NPs in $48 \mathrm{~h}$ effective concentration $50\left(\mathrm{EC}_{50}\right)$ values for Daphnia magna with suspensions of $60 \mathrm{~nm}$ and $300 \mathrm{~nm}$ AgNPs, and were found to be 1.0 (95\% confidence interval $(\mathrm{CI})=0.1-1.3) \quad$ and $\quad 1.4 \quad(95 \% \quad \mathrm{CI}=0.3-2.1) \quad \mu \mathrm{g} \quad \mathrm{Ag} / \mathrm{l}$, respectively, and for Oryzias latipes for $96 \mathrm{~h}$; $\mathrm{LC}_{50}$ values of 60 and $300 \mathrm{~nm} \mathrm{Ag} \mathrm{NPs} \mathrm{suspensions} \mathrm{were} 28$ (95\% $\mathrm{CI}=23-34)$ and $67 \quad(95 \% \quad \mathrm{CI}=45-108) \quad \mu \mathrm{g} \quad \mathrm{Ag} / \mathrm{l}$, respectively, and there was no acute toxicity with the $\mathrm{Ag}$ NPs suspensions not containing Ag+ [35]. The highest adult mortality was found in methanol extract of $A$. paniculata against the adults of $C x$. quinquefasciatus and Ae.aegypti with the $\mathrm{LC}_{50}$ and $\mathrm{LC}_{90}$ values of 149.81 and $172.37 \mathrm{ppm}$ and 288.12 and $321.01 \mathrm{ppm}$, respectively [20].

Bagavan, et al. [34] reported the leaf hexane extract of Annona squamosa and methanol extracts of Gloriosa superba and Phyllanthus emblica against $H$. bispinosa with $\mathrm{LC}_{50}=145.39,225.57$, and $256.08 \mathrm{ppm}$, respectively. The benzene, hexane, ethyl acetate, methanol, and chloroform leaf extract of $A$. paniculata was found to be more effective against $C x$. quinquefasciatus than Ae. aegypti. The $\mathrm{LC}_{50}$ values were $112.19,137.48,118.67,102.05$, and 91.20 and $119.58,146.34,124.24,110.12$, and $99.54 \mathrm{ppm}$, respectively [36]. The larvicidal activity of AgNPs synthesized using Sida acuta plant leaf extract against late third instar larvae of An. stephensi, Cx. quinquefasciatus, and Ae.aegypti was determined. The efficacies of synthesized AgNPs (10, 20, 30, 40, and $50 \mu \mathrm{g} \mathrm{mL}^{-1}$ ) and aqueous leaf extract $(50,100,150,200$, and $250 \mu \mathrm{g} \mathrm{mL}-1)$ were tested against the larvae of $C x$. quinquefasciatus ( $\mathrm{LC}_{50} 26.13$ and $130.30 \mu \mathrm{g} \mathrm{mL}^{-1}$ ), An. stephensi ( $\mathrm{LC}_{50} 21.92$ and $109.94 \mu \mathrm{g} \mathrm{mL}^{-1}$ ), and Ae.aegypti $\mathrm{LC}_{50}$ (23.96 and $119.32 \mu \mathrm{g} \mathrm{mL}^{-1}$ ), respectively [10]. Synthesized AgNPs using Tinospora cordifolia extract tested against the larvae of An. subpictus ( $\mathrm{LC}_{50}=6.43 \mathrm{mg} / \mathrm{l}$ ) and against the larvae of CX. quinquefasciatus ( $\mathrm{LC}_{50}=6.96 \mathrm{mg} / \mathrm{l}$ ) [17]. Batabyal, et al. [35] reported larvicidal responses of seed extracts of plants, Azadirachta indica $\left(\mathrm{LC}_{50}\right.$ of $\left.131.32 \mathrm{ppm}\right)$, Ricinus communis ( $\mathrm{LC}_{50}$ of $194.98 \mathrm{ppm}$ ), and Momordica charantia $\left(\mathrm{LC}_{50}\right.$ of $\left.87.00 \mathrm{ppm}\right)$, to An. stephensi larvae. The $\mathrm{LC}_{50}$ values of benzene, hexane, ethyl acetate, methanol, and chloroform extract of E. alba against early third instar larvae of Ae.aegypti were 151.38, 165.10, 154.88, 127.64, and $146.28 \mathrm{ppm}$, respectively [22]. Veerakumar and Govindarajan, et al. [24] reported the synthesized AgNPs against the adult of An. stephensi $\left(\mathrm{LD}_{50}=26.712 \mu \mathrm{g} / \mathrm{mL}\right.$; $\left.\mathrm{LD}_{90}=49.061 \mu \mathrm{g} / \mathrm{mL}\right)$, Ae.aegypti $\left(\mathrm{LD}_{50}=29.626 \mu \mathrm{g} / \mathrm{mL}\right.$; $\mathrm{LD}_{90}=54.269 \mu \mathrm{g} / \mathrm{mL}$ ), and $C x$. quinquefasciatus $\left(\mathrm{LD}_{50}=32.077 \mu \mathrm{g} / \mathrm{mL} ; \mathrm{LD}_{90}=58.426 \mu \mathrm{g} / \mathrm{mL}\right)$, respectively.
The highest larvicidal activity was observed in the essential oil from Zingiber officinale against $C x$. tritaeniorhynchus and An. subpictus with the $\mathrm{LC}_{50}$ and $\mathrm{LC}_{90}$ values as 98.83 and 57.98 and 186.55 and 104.23 ppm, respectively [36]. In conclusion, our study reveals that the synthesis of $A$. indica has remarkable larvicidal properties. The flora of India has rich aromatic plant diversity with potential for development of natural insecticides for control of mosquito and other pests. In brief, our findings suggested that the synthesis from $A$. indica aqueous leaf extract and its effective constituents may be explored as a potential environmental benign larvicide. Further investigations for the mode of the constituents' actions, effects on no target organisms and field evaluation are necessary. These results obtained are useful in search of more selective, biodegradable, and naturally produced larvicidal compounds. In conclusion, an attempt has been made to evaluate the role of medicinal plant extracts for their larvicidal bioassay against An. stephensi, Ae. aegypti and $C x$. quinquefasciatus. The results reported in this study open the possibility for further investigations of the efficacy of larvicidal properties of natural product extracts. The synthesized AgNPs and aqueous extract of $A$. indica are in progress.

\section{References}

1. Jang YS, Kim MK, Ahn YS, Lee HS (2002) Larvicidal activity of Brazilian plant against Aedes aegypti and Culex pipiens (Diptera: Culicidae). Agri Chem Biotechnol 4: 131-134.

2. Pancharoen C, Kulwichit $\mathrm{W}$, Tantawichien $\mathrm{T}$, Thisyakorn U, Thisyakorn C (2002) Dengue infection: a global concern. JMed Assoc Thai 85(S1): 25-33.

3. Mittal PK, Adak T, Subbarao SK (2005) Inheritance of resistance to Bacillus sphaericus toxins in a laboratory selected strain of An. stephensi (Diptera: Culicidae) and its response to Bacillus thuringiensis var. israelensis. Curr Sci 89: 442-443.

4. Snow RW, Guerra CA, Noor AM, Myint HY, Hay SI (2005) The global distribution of clinical episodes of Plasmodium falciparum malaria. Nature 434(7030): 214-217.

5. Peng Z, Beckett AN, Engler RJ, Hoffman DR, Ott NL, et al. (2004) Immune responses to mosquito saliva in 14 individuals with acute systemic allergic reactions to mosquito bites. J Allergy Clin Immunol 114(5): 11891194. 


\section{International Journal of Zoology and Animal Biology}

6. WHO (1992) Lymphatic filariasis: the disease and its control, fifth report of the WHO Expert Committee on Filariasis. Technical Report Series pp: 821.

7. Ranson H, Rossiter L, Ortelli F, Jensen B, Wang XL, et al. (2001) Identification of a novel class of insect glutathione S-transferases involved in resistance to DDT in the malaria vector Anopheles gambiae. Biochem J 359(pt 2): 295-304.

8. Bernhard L, Bernhard P, Magnussen P (2003) Management of patients with lymphoedema caused by filariasis in north-eastern Tanzania: alternative approaches. Physiotherapy 89(12): 743-749.

9. National Institute of Communicable Diseases (1990) Proceedings of the national seminar on operation research on vector control in filariasis.

10. Veerakumar K, Govindarajan M (2013) Green synthesis of silver nanoparticles using Sida acuta (Malvaceae) leaf extract against Culex quinquefasciatus, Anopheles stephensi and Aedes aegypti (Diptera: Culicidae). Parasitol Res 112(12): 4073-4085.

11. Sukumar K, Perich MJ, Boobar LR (1991) Botanical derivatives in mosquito control: a review. J Americ Mosq Control Assoc 72(2): 210-237.

12. Ignacimuthu S (2000) The root of botanicals in combating mosquitoes. Abstracts: Proceedings of symposium on recent trends in combating mosquitoes, Loyola College, Chennai, India pp: 19.

13. Wiseman Z, Chapagain BP (2005) Larvicidal effects of aqueous extracts of Balanites aegyptiaca (desert date) against the larvae of Culex pipiens mosquitoes. Afr J Biotechnol 4(11): 1351-1354.

14. Chen JC, Lin ZH, Ma XX (2003) Evidence of the production of silver nanoparticles via pretreatment of Phoma sp. 3.2883 with silver nitrate. Lett Appl Microbiol 37(2): 105-108.

15. Olagbemiro TO, Birkett MA, Mordue AJ, Pickett JA (1999) Production of (5R, 6S)-6-acetoxy-5hexadecanolide, the mosquito oviposition pheromone, from the seed oil of the summer cypress plant, Kochia scoparia (Chenopodiaceae). J Agric Food Chem 47: 3411-3415.
16. Veerakumar K, Govindarajan M (2014) Adulticidal properties of synthesized silver nanoparticles using leaf extracts of Feronia elephantum (Rutaceae) against filariasis, malaria, and dengue vector mosquitoes. Parasitol Res 113(11): 4085-4096.

17. Jayaseelan C, Rahuman AA, Rajakumar G, Santhoshkumar T, Kirthi AV, et al. (2012) Efficacy of plant-mediated synthesized silver nanoparticles against hematophagous parasites. Parasitol Res 111(2): 921-933.

18. Govindarajan M (2010) Larvicidal efficacy of Ficus benghalensis L. plant leaf extracts against Culex quinquefasciatus Say, Aedes aegypti L. and Anopheles stephensi L. (Diptera: Culicidae). Eur Rev Med Pharmacol Sci 14(2): 107-111.

19. Veerakumar K, Govindarajan M, Muthukumaran U (2014) Mosquito larvicidal properties of silver nanoparticles synthesized using Heliotropium indicum (Boraginaceae) against Aedes aegypti, Anopheles stephensi, and Culex quinquefasciatus. (Diptera: Culicidae). Parasitol Res 113(6): 2363-2373.

20. Govindarajan M, Sivakumar R (2012) Adulticidal and repellent properties of indigenous plant extracts against Culex quinquefasciatus and Aedes aegypti (Diptera: Culicidae). Parasitol Res 110(5): 1607-1620.

21. Bansal SK, Singh KV, Kumar S (2009) Larvicidal activity of the extracts from different parts of the plant Solanum xanthocarpum against important mosquito vectors in the arid region. J Environ Biol 30(2): 221-226.

22. Govindarajan M, Karuppannan P (2011) Mosquito larvicidal and ovicidal properties of Eclipta alba (L.) Hassk (Asteraceae) against chikungunya vector, Aedes aegypti (Linn.) (Diptera: Culicidae). Asian Pacific J Trop Med 4(1): 24-28.

23. Elumalai EK, Prasad TN, Hemachandran J, Therasa VS, Thirumalai T, et al. (2010) Extracellular synthesis of silver nanoparticles using leaves of Euphorbia hirta and their antibacterial activities. J Pharm Sci Res 2(9): 549-554.

24. Veerakumar K, Govindarajan M, Hoti SL (2014) Adulticidal activity of silver nanoparticles (AgNPs) synthesized Using Heliotropium indicum plant leaf extract against adults of Anopheles stephensi, Aedes aegypti, and Culex quinquefasciatus. Parasitol Res. 


\section{International Journal of Zoology and Animal Biology}

25. Prajapati V, Tripathi AK, Aggarwal KK, Khanuja SPS (2005) Insecticidal, repellent and ovipositiondeterrent activity of selected essential oils against Anopheles stephensi, Aedes aegypti and Culex quinquefasciatus. Bioresour Technol 96: 1749-1757.

26. Priyadarshini KA, Murugan K, Panneerselvam C, Ponarulselvam S, Hwang JS, et al. (2012) Biolarvicidal and pupicidal potential of silver nanoparticles synthesized using Euphorbia hitra against Anopheles stephensi Liston (Diptera: Culicidae). Parasitol Res 111(3): 997-1006.

27. Govindarajan M (2010) Chemical composition and larvicidal activity of leaf essential oil from Clausena anisata (willd.) Hook. F. Benth (Rutaceae) against three mosquito species. Asian Pacific J Trop Med 3(11): 874-877.

28. Santhoshkumar T, Rahuman AA, Rajakumar G, Marimuthu S, Bagavan A, et al. (2011) Synthesis of silver nanoparticles using Nelumbo nucifera leaf extract and its larvicidal activity against malaria and filariasis vectors. Parasitol Res 108(3): 693-702.

29. World Health Organization (2005) Guidelines for laboratory and field testing of mosquito larvicides communicable disease control, prevention and eradication, WHO pesticide evaluation scheme.

30. Finney DJ (1971) probit analysis. $2^{\text {nd }}$ (Edn.) Cambridge University Press, London, 60(9): 68-78.
31. Marimuthu S, Rahuman AA, Rajakumar G, Santhoshkumar T, Kirthi AV, et al. (2011) Evaluation of green synthesized silver nanoparticles against parasites. Parasitol Res 108(6): 2212-2224.

32. Kamaraj C, Rahuman AA, Mahapatra A, Bagavan A, Elango G (2010) Insecticidal and larvicidal activities of medicinal plant extracts against mosquitoes. Parasitol Res 107(6): 1337-1349.

33. Kim J, Kim S, Lee S (2010) Differentiation of the toxicities of silver nanoparticles and silver ions to the Japanese medaka (Oryzias latipes) and the cladoceran Daphnia magna. Nanotoxicol 5(2): 208-214.

34. Bagavan A, Kamaraj C, Elango G, Zahir AA, Rahuman AA (2009) Adulticidal and larvicidal efficacy of some medicinal plant extracts against tick, fluke and mosquitoes. Vet Parasitol 166(3-4): 286-292.

35. Govindarajan M (2011) Larvicidal and repellent properties of some essential oils against Culex tritaeniorhynchus Giles and Anopheles subpictus Grassi (Diptera: Culicidae). Asian Pac J Trop Med 4(2): 106-111.

36. Batabyal L, Sharma P, Mohan L, Maurya P, Srivastava CN (2007) Larvicidal efficiency of certain seed extracts against Anopheles stephensi, with reference to Azadirachta indica. J Asia Pacific Entomol 10(3): 251-255. 